\title{
BINGE WATCHING AND CLINICAL DEPRESSION- ONE HARBINGER FOR ANOTHER?
}

\author{
Dr. Ankit Halder* 1 \\ ${ }^{1}$ Second Year Junior Resident, \\ Department of Psychiatry \\ Dr. Abhishek Das ${ }^{3}$ \\ ${ }^{3}$ Third Year Junior Resident, \\ Department of Pathology
}

\author{
Dr. Navna Panchami Ravindran ${ }^{2}$ \\ ${ }^{2}$ First Year Junior Resident, \\ Department of Psychiatry
}

\section{*Corresponding Author}

\begin{abstract}
Television is one of our most preferred forms of entertainment. Due to the emergence of smartphones and online streaming platforms television is now in our hands and pockets constantly. Depression may be positively related to television viewing affinity. Individuals higher in depression were more likely to binge-watch television shows out of comfort seeking. It also seemed possible that individuals who had higher in depression lack the motivation or cognitive energy to resist the auto-play functions of streaming products. Viewers tend to binge watch more in order to forget temporarily about every day life stress due to work and social life that are the hallmark of many depressive episodes. Still, the cause and effect relationship could not be established properly; it is not known whether the depressed people tend to binge-watch more for the reasons mentioned or the binge watching leads to depression. It is therefore reasonable to conclude that both depression and binge watching in many ways can be prelude for the other. So, it is plausible to conduct further studies on pathophysiology of binge watching and depression and to find the core behind the link between them.
\end{abstract}

KEYWORDS: Binge-watching,Depression,Smartphomes

\section{INTRODUCTION}

Television is one of our most preferred forms of entertainment. Due to the emergence of smartphones and online streaming platforms television is now in our hands and pockets constantly.[1] Depression may be positively related to television viewing affinity. Individuals higher in depression were more likely to binge- watch television shows out of comfort seeking. It also seemed possible that individuals who had higher in depression lack the motivation or cognitive energy to resist the auto- play functions of streaming products. Viewers tend to binge watch more in order to forget temporarily about everyday life stress due to work and social life that are the hallmark of many depressive episodes[2].

\section{DISCUSSION}

Television is one of our most favorite forms of entertainment. Studies have shown that, up to 30 to $40 \%$ of adults spend about 4 hours daily spending on Television (TV) [1].In present scenario, watching TV need not always involve a television set. Thanks to the 
emergence of smartphones and online streaming platforms, like Netflix, Hotstar, Amazon Prime and countless others, television is now in our hands and pockets constantly. Users also are relieved of making any payments to cable services, contracts, copyright violations and importantly, boredom! [3]

The TV series nowadays have become very sophisticated with complex narrative structures and dramatic techniques that is directed at keeping viewers "hooked".As a result of this, the watching of several episodes of one series has become a popular pattern of viewing.Despite having no empirically validated definition,several authors recommend watching $>2$ episodes in one sitting as a criterion for bingewatching[4].

Key motives for binge-watching are emotional enhancement and coping.Binge-watching might serve as an easy way to escape reality and avoid negative emotions [5]. Individuals experiencing negative emotions and having difficulties applying adaptive coping strategies might tend to engage in excessive binge-watching as a coping approach. Furthermore, individuals who depend on using media to regulate their restless moods might find it difficult to stop using media. A lack of self-regulation can have a mediating effect on depression and media addiction. This contributes to excessive media consumption. Furthermore, depression symptoms may also affect subjective time flow. This leads to the perception of time passing slowly. This phenomenon might attempt individual to binge-watching [5].

Depression may be positively related to television viewing affinity. It is reasonable to assume that individuals that view television for instrumental reasons may have a greater affinity for viewing television than those who view television for ritualistic purposes. Viewing television for instrumental purposes is associated with higher scores of depression[2]. Participants high in depression tended to report higher levels of watching television for both ritualistic and instrumental or purposeful motivations, such as to gain information or for engaging entertainment, and these individuals also reported higher frequencies of engaging in binge-watching behavior.Individuals higher in depression were more likely to binge- watch television shows out of comfort seeking. It also seemed possible that individuals who had higher in depression lack the motivation or cognitive energy to resist the auto- play functions of streaming products[2].

Retrospectively, depression scores can be higher in binge watchers than on-binge-watchers[6]. So,depression can make the person attempt to escape from his condition to watch more TV acts as stress buster[7].More an individual was depressed, themore episodes the individual watched[6]. Literature on uses and gratification provide media scholars with many signs of having "escape from reality is the primary motive behind intensive TV watching. Viewers tend to watch moreTV in order to forget temporarily about every day life stress due to work and social life.However,the cause andeffect could not be claimed; it is not knowm whether the depressed people tend to binge-watch more for the reasons mentioned or the binge watching leads to depression as viewers might regret spending many hours in one session watching a whole session of a TV programme[5]

Another study though reported a negative relation between depression and binge-watching, and no connection between self-control,loneliness and binge-watching[7].

\section{CONCLUSION}

It is therefore fair to conclude that both depression and binge watching in many ways can be prelude for the other.Both can thus be an harbinger for one another and should be carefully probed into during history and management of presentation with such symptoms.Thus, it is plausible to conduct further studies on pathophysiology of binge watching and depression and to find the core behind the connection between them.

\section{REFERENCES}

1. Stamatakis E, Hillsdon M, Mishra G, et al. (2009) Television viewing and other screen-based entertainment in relation to multiple socioeconomic status indicators and area deprivation: The Scottish Health Survey 2003. Journal of Epidemiology \& Community Health 63: 734-740.

2. Wheeler KS. The relationships between television viewing behaviors, attachment, loneliness, depression, and psychological well-being

3. Pendlebury T, Katzmaier D. Best live TV streaming services for cord cutters. August 11 $2019 . \quad$ Downloaded from https://www.cnet.com/news/best-live-tvstreaming-services-for-cord-cutters/ on August 15 2019.

4. Steins-Loeber S, Reiter T, Averbeck H, Harbarth L, Brand M. Binge-Watching Behaviour: The Role of Impulsivity and Depressive Symptoms. European addiction research. 2020;26(3):141-50.

5. Sun JJ, Chang YJ. Associations of problematic binge-watching with depression, social interaction anxiety, and loneliness. International journal of environmental research and public health. 2021 Jan;18(3):1168.

6. Ahmed AA. New era of TV-watching behavior: Binge watching and its psychological effects. Media Watch. 2017;8(2):192-207. 
7. Sung YH, Kang EY, Lee WN. Why do we indulge? Exploring motivations for binge watching. Journal of Broadcasting \& Electronic Media. 2018 Jul 3;62(3):408-26.

8. Tefertiller AC, Maxwell LC. Depression, emotional states, and the experience of binge-watching narrative television. Atlantic Journal of Communication. 2018 Oct 20;26(5):278-90 